\title{
Structural Investigation of a Novel Sulfonamide Chalcone Hybrid
}

Lidiane J. Michelini, Jean M. F. Custodio, Mirian Rita C. de Castro, Caridad N. Perez and Hamilton B. Napolitano Universidade Federal de Goiás

Sulfonamides are important organic molecules to study regarding their wide range of reported biological activities $^{1}$. In this way, hybrid compounds such as sulfonamide chalcones (a fusion of sulfonamide and chalcone moieties) conserve or even increase their biological activities ${ }^{1-3}$. The synthesis and structural analysis of a new sulfonamide chalcone (2,5-dichloro-N-\{3-[(2E)-3-(4-nitrophenyl)prop-2-enoyl]phenyl $\}$ benzene-1-sulfonamide) $(\mathrm{SCH})$ are reported in this work. Single crystal X-ray diffraction of SCH was collected on Bruker APEX II CCD diffractometer. The refinement of the structure $(\mathrm{R} 1=5.79 \%$ and Goof $=1.068)$ was made by SHELX suit programs and indicates the centrosymmetric monoclinic space group $\mathrm{C} 2 / \mathrm{c}$, obtained after squeeze by Platon software. Figure 1(a) shows an ortep representation of SCH. The quasi planarity of the chalcone portion is confirmed by the angle of $5.23^{\circ}$ formed between the planes of its aromatic rings, whereas the sulfonamide moiety is almost perpendicular to it $\left(85.72^{\circ}\right)$. Hydrogen bonded dimers are linked in a chain by $\mathrm{C}-\mathrm{H} \cdots \mathrm{O}$ interaction, involving the nitrobenzene aromatic ring. These chains form a layer associated by interactions around sulfone and nitro groups. Finally, the crystal packing is obtained by stacking these dimeric chains, intercalating chalcone moieties and sulfonamides aromatic rings. The solvent accessible voids were found with $13.2 \%$ of unit cell volume, as shown in Figure 1(b). Hirshfeld surface analysis were performed before SQUEEZE and indicates that crystal packing is also stabilized by both $\pi \cdots \pi$ and $\mathrm{C}-\mathrm{H} \cdots \pi$ interactions.

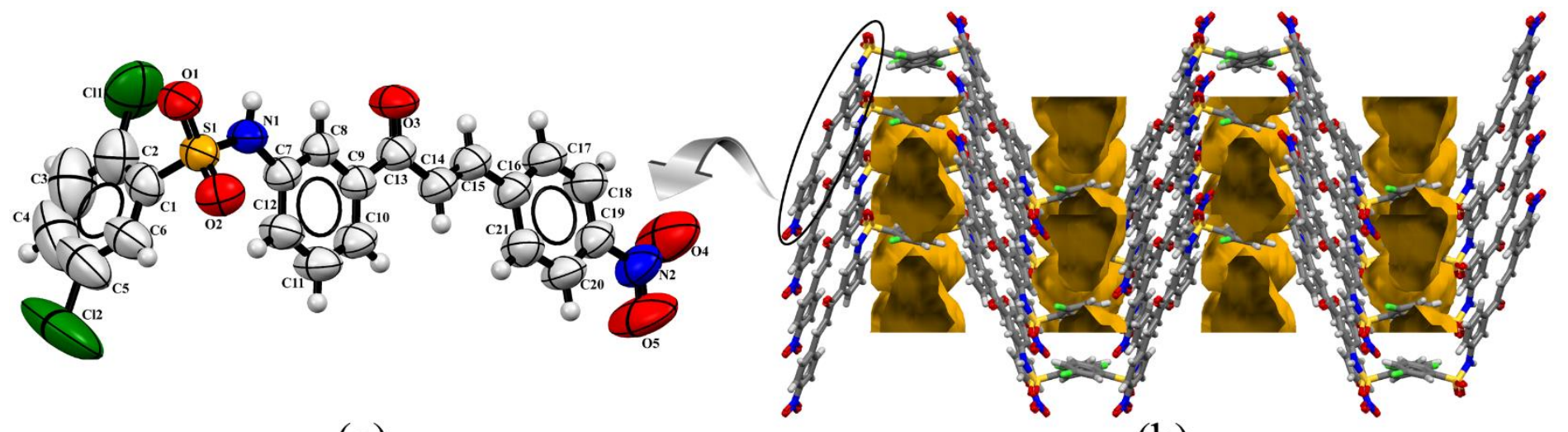

(a)

(b)

Figure 1: Ortep representation of ellipsoids at 50\% probability level of SCH (a) and its crystal packing (b). Voids are represented by yellow color.

\section{Acknowledgements:}

The authors would like to thank the Brazilian agency Coordenação de Aperfeiçoamento Pessoal de Nível Superior (CAPES) for financial support.

\section{References:}

1 N. S. El-sayed, E. R. El-bendary, S. M. El-ashry and M. M. El-kerdawy, Eur. J. Med. Chem., 2011, 46, 3714-3720.

2 P. Graziela, A. Martins, A. Camila, O. Menegatti, L. D. Chiaradia-delatorre, K. Navakoski, D. Oliveira, R. Victorio, C. Guido, A. De, J. Vernal, R. Augusto, R. José and H. Terenzi, Eur. J. Med. Chem., 2013, 64, 35-41.

3 V. Yerragunta, T. Kumaraswamy, D. Suman, V. Anusha, P. Patil and T. Samhitha, PharmaTutor, 2013, 1, 54-59. 